\title{
Produção de vídeo aulas como ferramenta educacional no processo de ensino e aprendizagem de física no ensino médio
}

\author{
Daniele Socorro Ribeiro da Silva ${ }^{1}$, Jayanny Sá Santos², Sandro Mateus Ferreira Teixeira ${ }^{3}$ \\ 1,2,3 Instituto Federal de Educação, Ciência e Tecnologia do Pará (IFPA) - Bragança
}

Palavras-Chave: Produção, Vídeo-aula, Ensino, Física.

\section{Introdução}

Atualmente no ensino médio, a Física é vista por muitos alunos como uma disciplina de difícil acesso e pouco atraente. Sem apoio do professor, a relação entre a disciplina de física e o aluno pode se tornar obsoleta, gerando assim, dificuldades no processo de ensino e de aprendizagem, fazendo com que a física não seja compreendida em sua totalidade. Outro fator que pode influenciar nesse cenário, é o fato de que algumas vezes, as metodologias usadas para o ensino de Física não são inovadoras, predominando um ensino descontextualizado e sem significado para o aluno.

Este trabalho traz como suporte a teoria da aprendizagem significativa, que foi enunciada inicialmente pelo psicólogo e pesquisador norte americano David Paul Ausubel (1918-2008). Essa teoria é baseada em uma abordagem cognitivista da construção do conhecimento, onde resulta no armazenamento organizado de informações na mente daquele que aprende. De acordo com David Ausubel (apud MOREIRA, 2006, p. 14), "É um processo pelo qual uma nova informação se relaciona, de maneira substantiva (não literal) e não arbitrária, a um aspecto relevante da estrutura cognitiva do indivíduo", ou seja, se a intenção do professor é ensinar de maneira significativamente, é necessário que o mesmo avalie aquilo que o aluno já sabe e então ensinar conforme com esses conhecimentos.

Neste sentido, as possibilidades da produção e uso do vídeo em sala de aula proporcionam a inovação no processo ensino e aprendizagem, pois o vídeo pode estimular a construção do conhecimento de forma ativa, atrativa, criativa e significativa. Dessa forma, o professor pode proporcionar ao aluno uma aprendizagem mais significativa e próxima ao seu cotidiano, além de permitir que ele saia do papel de ouvinte, tornando-se o principal agente na formação do próprio conhecimento e apto a sugerir soluções e condições que proporcionem a própria aprendizagem.

\section{Materiais e Métodos}

A pesquisa ocorreu no Instituto Federal do Pará, Campus Bragança, com as turmas do $3^{\circ}$ ano do ensino médio integrado dos cursos técnicos em Eventos e Edificações, totalizando 38 alunos. Foi feita uma intervenção pedagógica na disciplina de Física com o tema carga elétrica e Corrente elétrica, com o auxílio de 2 estudantes da graduação em Física do mesmo instituto. Os alunos dos cursos de eventos e edificações foram motivados a criarem vídeo-aulas sobre os temas abordados e postarem seus trabalhos em uma comunidade virtual. $O$ objetivo foi identificar se a produção de vídeo-aulas pode proporcionar uma aprendizagem mais significativa para o aluno. Nesse sentido, foi aplicado um pré-teste a fim de observar o conhecimento prévio que os alunos tinham sobre o assunto, e um pós-teste visando diagnosticar se houve uma aprendizagem com significação para os alunos.

A metodologia aplicada foi baseada nos princípios de Gil (2008), contemplando a pesquisa de campo, que além de ser uma etapa importante, cuja função é extrair dados e informações diretamente da realidade do objeto de estudo, também determina os objetivos e hipóteses da pesquisa, bem como a melhor forma para coletar os dados necessários como a utilização de entrevistas ou questionários avaliativos, que oferecerão respostas para o problema da pesquisa.

Nesse sentido, foi utilizado como procedimento a pesquisação com o propósito de melhor explicar os efeitos da produção de vídeo aulas como ferramentas didáticas no processo de ensino e aprendizagem de Física. O presente trabalho resume uma pesquisa qualitativa, pois visa entender as causas dos resultados obtidos de maneira mais profunda, no sentido de complementar a análise em busca da eficácia no estudo. 


\section{Resultados E Discussões}

Ao verificar o nível de desempenho dos alunos antes da produção dos vídeos em relação ao assunto de Carga Elétrica e Corrente Elétrica por meio do questionário avaliativo, verifica-se que quase todos tiveram desempenho um pouco abaixo do esperado. Dessa forma, corrobora-se com o pensamento de Pedrosa (2015), que relata o quanto é importante mostrar a parte teórica e pratica da ciência, pois percebe-se que o estudante muitas vezes não consegue associar o conhecimento ao seu cotidiano.

Sendo assim, a análise nos permite deduzir que os alunos do ensino médio, geralmente, encontram algumas dificuldades na aplicação de equações físicas sobre fenômenos elétricos, principalmente quando se utiliza de um método tradicional, sem influência das tecnologias, o que acaba dificultando em muitos casos, o aprendizado dos alunos.

A atividade diferenciada não só ajudou os alunos a compreenderem o conteúdo de uma maneira mais ativa e colaborativa como melhorou os resultados da nova aplicação do questionário nas turmas envolvidas. Segundo Masetto (2000), o aluno aprende mais quando este é estimulado a vivenciar novas experiências colocando em prática seu aprendizado e estipulando um elo criativo e informativo entre a sua reflexão e sua ação. Percebeu-se também que, ao serem estimulados a produzir uma vídeo-aula, os alunos procuraram se aprofundar nos conteúdos sugeridos o que pode ter acarretado em uma aprendizagem com maior significação.

\section{Conclusões}

Ao final deste trabalho compreende-se que é importante buscar novas alternativas e ferramentas que possam ajudar o professor a superar as dificuldades no processo de ensino da Física, pois a maioria dos alunos a considera difícil e descontextualizada. Nesse sentido, é necessário que o professor esteja aberto e busque novas práticas para auxiliar no processo de Ensino.

Pelos resultados obtidos antes e depois da atividade utilizada na metodologia da pesquisa constata-se que ocorreu um progresso considerável na segunda abordagem de ensino. Portanto, com a produção do vídeo foi possível tornar os estudantes personagem principal na construção de conhecimento físico mais contextualizado e significativo.

Por meio das experiências e das sondagens realizadas através do questionário, percebeu-se que os alunos, em geral, gostaram de utilizar os recursos tecnológicos (celulares, câmeras fotográficas e entre outros) e demonstraram um grande envolvimento na produção de vídeo-aulas, realçando a criatividade na criação de sons, além de desenvolverem um trabalho de forma cooperativa tornando-os capazes de resolverem problemas cotidianos.

\section{5- Referências}

GIL, A. C. Como elaborar projetos de pesquisa. 4. ed. São Paulo: Atlas, 2008

MASETTO, M. T. Mediação pedagógica e o uso da tecnologia. In: Moran, José Manuel (Org.). Novas tecnologias e mediação pedagógica. Campinas, SP: Papirus, 2000.

MOREIRA, M. A.; MASINI, E. A. F. S. Aprendizagem significativa: a teoria de David Ausubel. 2 ed. São Paulo, Centauro, 2006.

PEDROSA, P. D. O uso das tecnologias de informação e comunicação na promoção da aprendizagem da termodinâmica. 2015. 107 f. Dissertação (Mestrado Profissional de Ensino de Física - MNPEF), Universidade Federal do Vale São Francisco. Programa de Pós-Graduação em Ensino de Física. Juazeiro da Bahia, 2017. Disponível em:<http://www1.fisica.org.br/mnpef/sites/default/files/dissertacao_pedrodavid.pdf>. Acesso em: 15 jun. 2018. 